\title{
Strategies for innervation of the neophallus
}

\author{
Rayisa Hontscharuk ${ }^{1}$, Charalampos Siotos ${ }^{1}$, Loren S. Schechter ${ }^{1,2,3}$ \\ 'Department of Plastic and Reconstructive Surgery, Rush University Medical Center, Chicago, IL 60612, USA. \\ ${ }^{2}$ Department of Plastic and Reconstructive Surgery, University of Illinois at Chicago, Chicago, IL 60612, USA. \\ ${ }^{3}$ The Center for Gender Confirmation Surgery, Weiss Memorial Hospital, Chicago, IL 60640, USA.
}

Correspondence to: Dr. Loren S. Schechter, The Center for Gender Confirmation Surgery, Weiss Memorial Hospital, 9000 Waukegan Rd Suite 210, Morton Grove, IL 60053, USA. E-mail: Iss@univplastics.com

How to cite this article: Hontscharuk R, Siotos C, Schechter LS. Strategies for innervation of the neophallus. Plast Aesthet Res 2020;7:65. http://dx.doi.org/10.20517/2347-9264.2020.124

Received: 25 May 2020 First Decision: 7 Sep 2020 Revised: 15 Sep 2020 Accepted: 23 Sep 2020 Published: 13 Nov 2020

Academic Editor: Marlon E. Buncamper Copy Editor: Cai-Hong Wang Production Editor: Jing Yu

\begin{abstract}
A fundamental goal of phalloplasty includes the construction of a sensate neophallus. Both tactile and erogenous sensation are important for protective sensation (including retention of implantable penile prosthesis) as well as sexual satisfaction. This article will describe the sensory innervation of flaps commonly used for phalloplasty including the radial forearm flap, anterolateral thigh flap, and musculocutaneous latissimus dorsi flap. The sensory innervation of the perineum and external genitalia will be reviewed as a basis for selecting recipient nerves. Additionally, surgical techniques, such as neurorrhaphy, will be discussed. Finally, outcome data, although limited, will be assessed.
\end{abstract}

Keywords: Phalloplasty, sensation, radial forearm flap, anterolateral thigh flap

\section{INTRODUCTION}

Recent studies estimate that approximately 25 million individuals worldwide, including 1 million people in the United States, identify as transgender ${ }^{[1-3]}$. Over the past several years, the demand for gender affirmation surgery has steadily increased ${ }^{[4]}$. The American Society of Plastic Surgeons reported that a total of 2,885 feminizing procedures and 6,691 masculinizing procedures were performed in 2018, representing an increase of $109 \%$ and $392 \%$, respectively, since $2015^{[5]}$. This includes an increase in the number of transgender men seeking consultation for "bottom" surgery; approximately $40 \%$ of whom ultimately undergoing a phalloplasty procedure ${ }^{[6]}$.

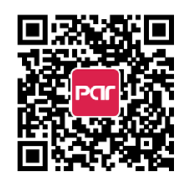


Table 1. Phalloplasty flap options

\begin{tabular}{|c|c|}
\hline Free flap options & Pedicled flap options \\
\hline Radial forearm flap ${ }^{[7,8,10,11,20-23,24-28,68]}$ & Anterolateral thigh flap ${ }^{[7,20,21,23,34,35,68]}$ \\
\hline Anterolateral thigh flap ${ }^{[7,21]}$ & Abdominal flaps $s^{[7,21]}$ \\
\hline Osteocutaneous fibula flap ${ }^{[7,27,42,70]}$ & Groin flap $^{[7]}$ \\
\hline Musculocutaneous latissimus dorsi flap ${ }^{[40,41]}$ & Gracilis flap ${ }^{[7]}$ \\
\hline Lateral arm flap ${ }^{[10,66]}$ & Superficial circumflex iliac artery perforator flap ${ }^{[45-47]}$ \\
\hline
\end{tabular}

Individuals who have undergone phalloplasty procedures express high rates of satisfaction ${ }^{[7]}$ and improved quality of life ${ }^{[8,9]}$. However, phalloplasty remains a complex procedure with no "one size fits all" approach. A variety of techniques are used to create an aesthetic and functional neophallus, with the most common being the radial forearm flap (RFF) and the anterolateral thigh flap (ALT). The goals of phalloplasty are well described; among these goals include the construction of a sensate neophallus, capable of providing both protective and erogenous sensation ${ }^{[10,11]}$. An individualized approach, utilizing a shared decision-making model, is recommended.

Restoring genital sensibility is highly desired by patients, and a sensate neophallus is a major determinant of postoperative satisfaction ${ }^{[10,12]}$. Tactile sensation is important in reducing the risk of inadvertent injuries as well as providing protection for subsequent implantable penile prostheses ${ }^{[13]}$. Erogenous sensation is sine qua non for sexual satisfaction and orgasm ${ }^{[14]}$. Microneurosurgical techniques used to restore sensation include coaptation of recipient flap nerves, such as the lateral and/or medial antebrachial cutaneous nerves or lateral femoral cutaneous nerves, to donor nerves in the groin and/or existing genitalia, such as the ilioinguinal, genitofemoral, and/or branches of the dorsal pudendal or dorsal clitoral nerves ${ }^{[15]}$.

The ideal approach to achieving sensation in the neophallus is yet to be identified. This review discusses common flaps used in phalloplasty procedures as well as strategies to optimize flap innervation. Relevant genital anatomy, nerve coaptation techniques, and outcomes data are reviewed.

\section{CURRENT PHALLOPLASTY FLAP OPTIONS}

The goals of phalloplasty include the provision of both tactile (protective) and erogenous sensation to facilitate orgasm and enhance sexual satisfaction. A variety of flap options are available [Table 1], with the most common being the RFF and ALT flaps.

The RFF is based on the radial artery, venae comitantes, and cephalic vein and can be harvested with the lateral and/or medial antebrachial cutaneous nerves [Figure 1]. The medial antebrachial cutaneous nerve originates from the medial cord of the brachial plexus. It travels through the arm, medial to the brachial artery. Distally, it becomes more superficial, running adjacent to the basilic vein. In the elbow, it divides into anterior and posterior branches. The anterior branch passes between the medial epicondyle and the biceps tendon, then travels superficially over the flexor carpi ulnaris at the level of the wrist. The posterior branch courses anterior to the elbow, then posteriorly over the flexor muscles ${ }^{[16,17]}$. The lateral antebrachial cutaneous nerve is the terminal branch of the musculocutaneous nerve. In the forearm, it lies in the subcutaneous fat, lateral to the biceps tendon. It then travels distally with the cephalic vein towards the 1 st and 2 nd extensor compartments of the wrist ${ }^{[18,19]}$.

The RFF's reliable neurovascular anatomy, including its innervation density, and its thin subcutaneous fat layer (helpful for flap shaping and a double tube procedure) make it a frequent "first-choice" option for phalloplasty [Figure 2] $]^{[7,10,20-26]}$. However, color mismatch, atrophy over time, and a conspicuous donor site may lead some individuals to select other flap options ${ }^{[7,10,20,21,24,27,28]}$. Morrison et al ${ }^{[7]}$ found that $78.1 \%$ of patients undergoing RFF phalloplasty were satisfied with the procedure. Within this group, $98.1 \%$ of 

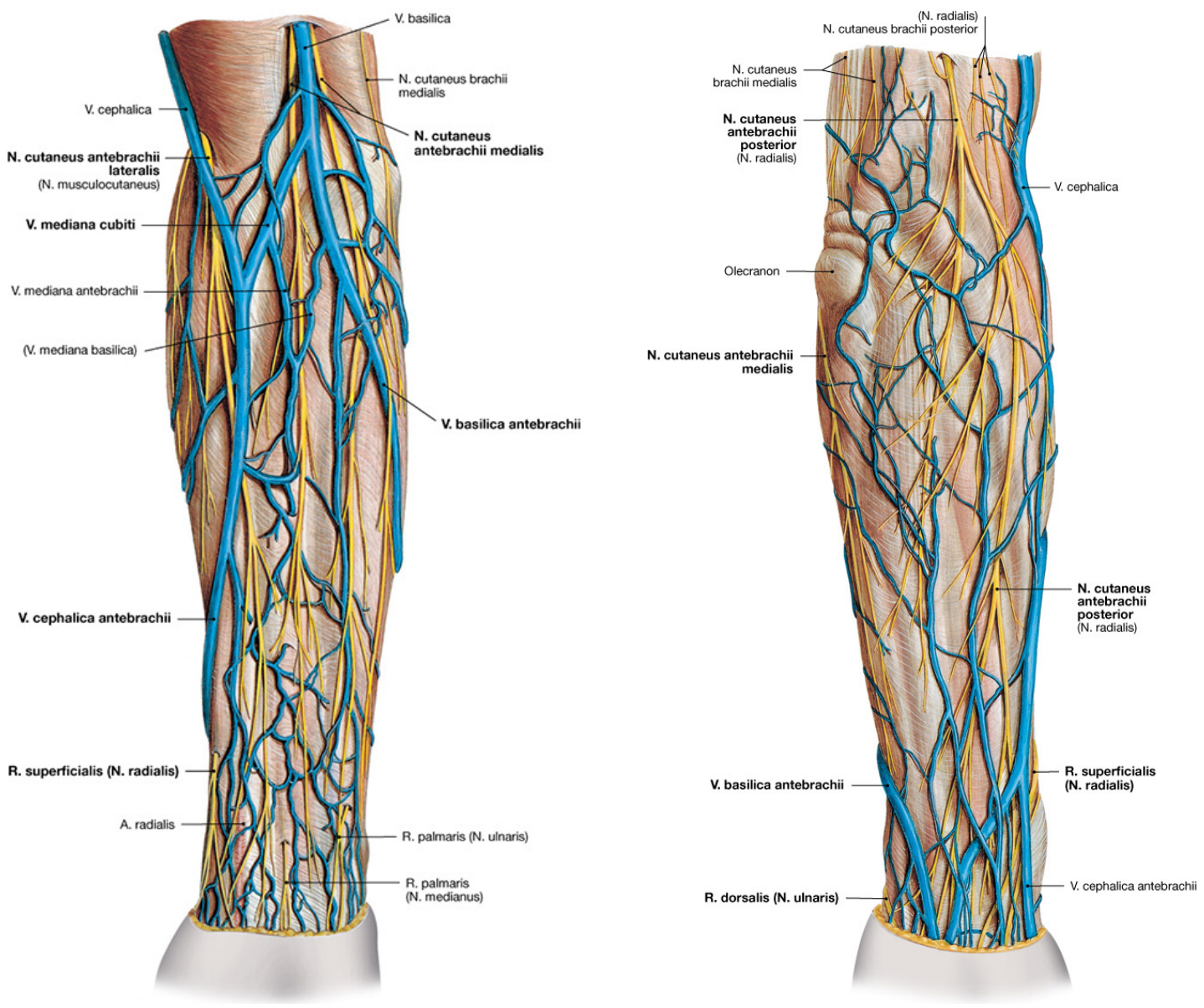

Figure 1. Superficial veins and cutaneous nerves of the forearm (volar and dorsal surface).

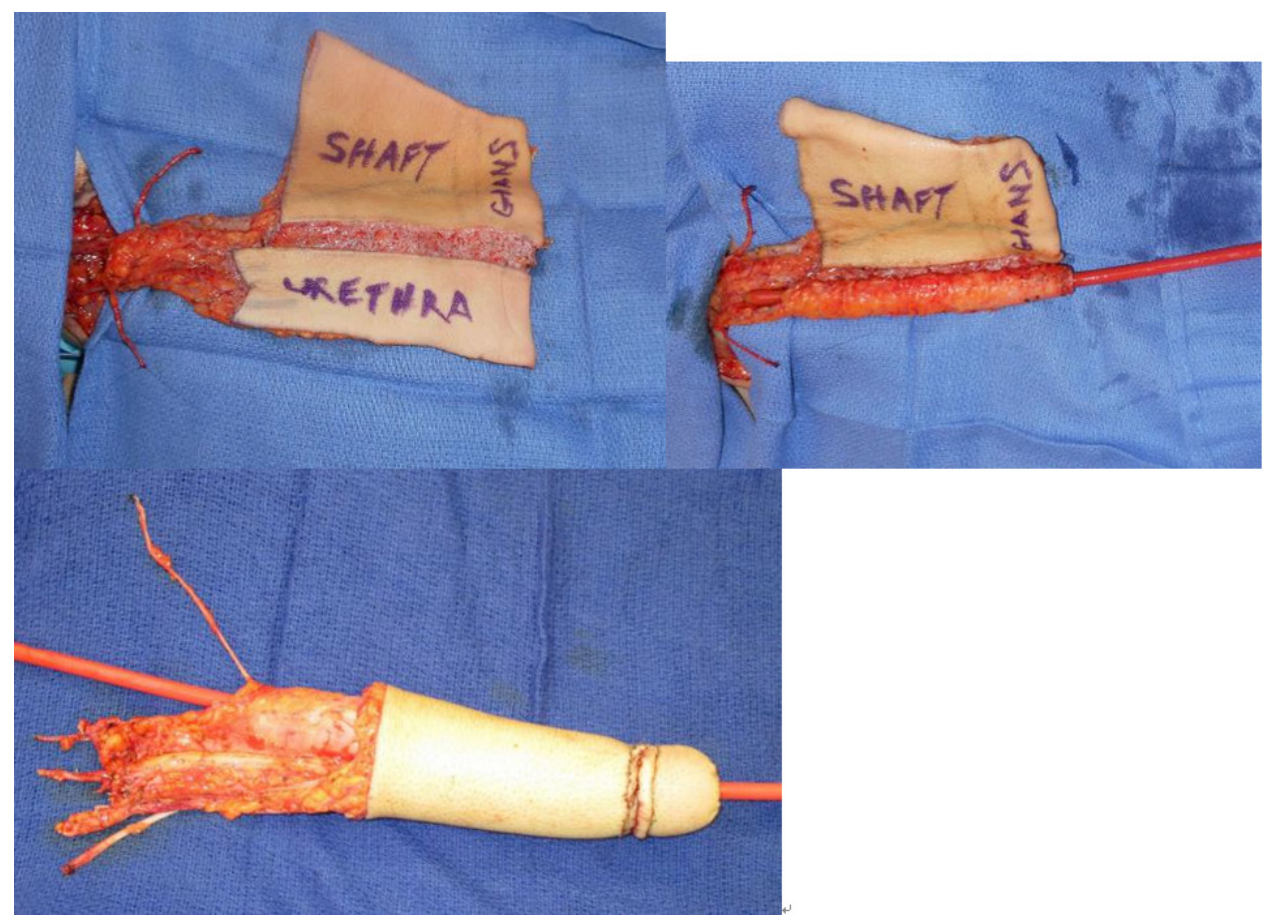

Figure 2. Design of the neophallus using a radial forearm free flap: tube within a tube procedure 


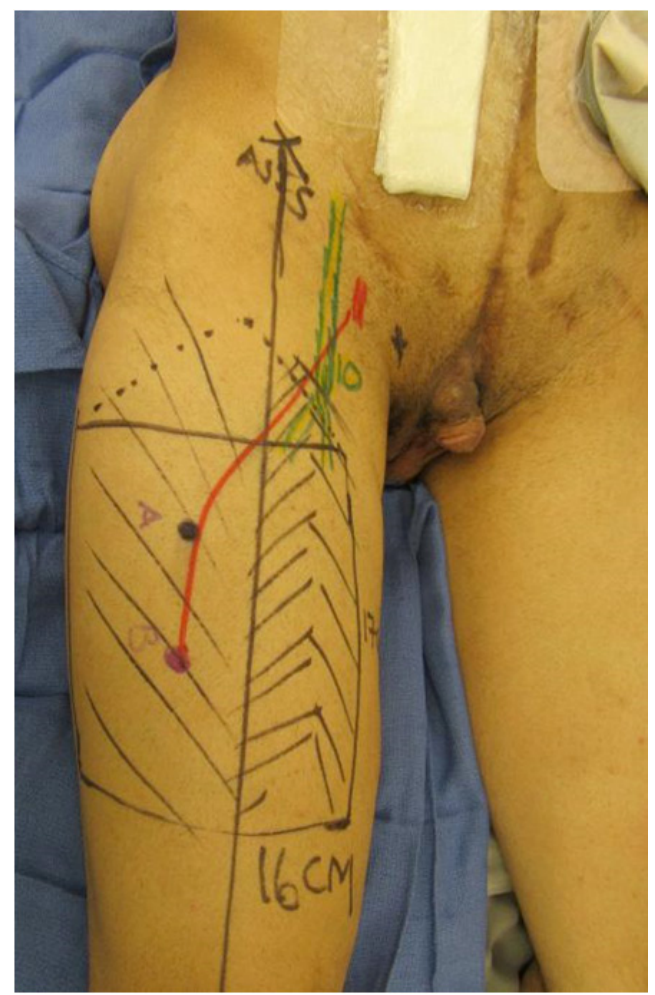

Figure 3. Preoperative marking for an Anterolateral thigh flap phalloplasty in a patient with exstrophy

patients reported tactile sensation, and $71.4 \%$ of patients reported the return of erogenous sensation. Monstrey et al. ${ }^{[24]}$ found that all patients regained tactile sensitivity 1 year following RFF phalloplasty. In addition, $>80 \%$ of patients reported sexual satisfaction, and $100 \%$ of patients were able to reach orgasm following surgery. Selvaggi et al.$^{[29]}$ found that pressure thresholds over the glans, corona, and shaft of the neophallus correlated well with cisgender penile controls. Also, Selvaggi et al ${ }^{[29]}$ found that $100 \%$ of patients who underwent RFF phalloplasty were able to experience orgasm following surgery. This is consistent with other reports confirming erogenous sensation in the neophallus following RFF phalloplasty ${ }^{[8,30,31]}$.

The ALT flap, another frequent choice for phalloplasty ${ }^{[7]}$, is based on the descending branch of the lateral circumflex femoral artery [Figure 3]. The flap can be harvested with the lateral femoral cutaneous nerve (LFCN), which provides sensation to the inferolateral thigh [Figure 4]. The LFCN emerges from the deep fascia, approximately $10 \mathrm{~cm}$ distal to the ASIS. It travels within the deep subcutaneous tissue and divides into three branches in the middle third of the thigh. The anterior branch is the largest ( 1 to $2 \mathrm{~mm}$ in diameter) and courses inferiorly along the vascular axis of the ALT flap.

Other sensory nerves, the superior perforator nerve, and the median perforator nerve arise from the lateral musculocutaneous nerve (the terminal branch of the femoral nerve) and lie within the anatomical boundaries of the ALT flap ${ }^{[32,33]}$. In the proximal portion of the flap, the superior and median perforator nerves are superficial. In the distal flap, the perforator nerves branch freely and repeatedly, gradually disappearing. Ribuffo et al. ${ }^{[32]}$ theorized that the superior and median perforator nerves can be included in the flap, in addition to the LFCN, to further optimize sensory reinnervation. The LFCN (classically used as the sole innervating nerve of the sensate ALT flap) has been shown to provide sensation to $100 \%$ of the ALT skin flap territory, whereas the median perforator nerve and superior perforator nerve supply sensation to approximately $60 \%$ and $25 \%$ of the medial aspect of the flap, respectively ${ }^{[32]}$. Insufficient data currently exist to recommend the routine inclusion of these nerves in the ALT flap harvest. 


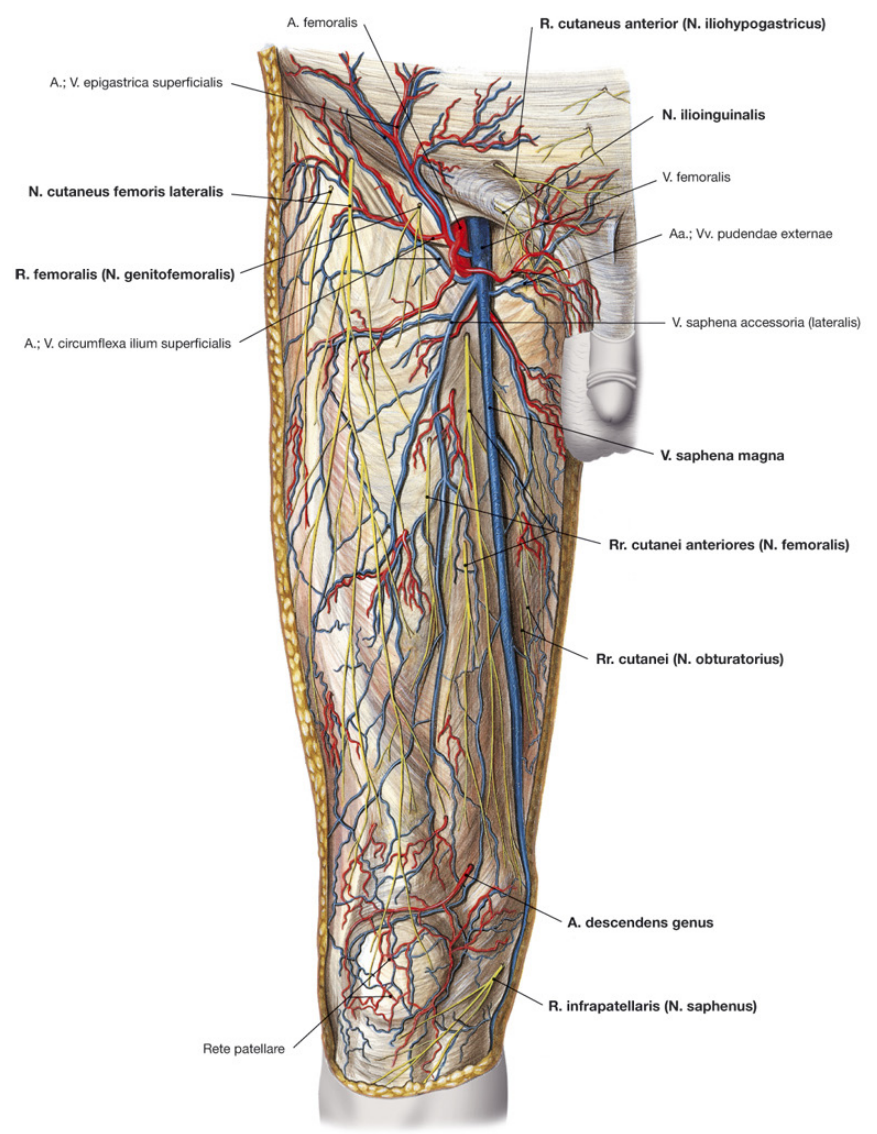

Paulsen/Waschke: Sobotta - Atlas der Anatomie, 24. A. 2017 @ Elsevier GmbH

Figure 4. Superficial nerves and blood vessels of the anterior thigh

The ALT flap offers a good color match, a less conspicuous donor site as compared to the RFF, and may be performed as a pedicled procedure ${ }^{[7,11,20,21,34,35]}$. The ALT flap may offer an advantage over the RFF by providing additional bulk, however, in many individuals, the amount of subcutaneous fat precludes its use in a double tube procedure ${ }^{[20,21]}$. Additionally, flap defatting should be undertaken with caution due to the risk of injury to the LFCN and subsequent loss of sensation in the flap ${ }^{[20]}$. When comparing a onestage ALT flap to a one-stage RFF (both performed with urethral lengthening and vaginectomy), the ALT flap was found to have a higher rate of postoperative complications ${ }^{[36]}$. Despite this, overall patient satisfaction remains high (reported at $100 \%)^{[7]}$. Following coaptation of the LFCN to the dorsal clitoral nerve, patients achieved tactile and erogenous sensation and reported satisfactory sexual function following surgery ${ }^{[7,34,37]}$. In a recent literature review, $75 \%$ of patients undergoing ALT phalloplasty reported tactile sensation, and $60 \%$ of patients undergoing reported erogenous sensation ${ }^{[7]}$. In a case study, Rubino et al. ${ }^{[34]}$ reported normal ranges of vibration and thermal sensation in the neophallus when compared to the left thenar eminence. The patient in this case report also experienced erogenous stimuli during penetrative intercourse.

The musculocutaneous latissimus dorsi (MLD) flap is another option, although not commonly used in North America. Its vascular supply is based upon the thoracodorsal system. While the thoracodorsal nerve can be harvested with the flap, this is primarily a motor nerve, supplying the latissimus dorsi muscle rather than the overlying skin. The thoracodorsal (or middle or long subscapular) nerve arises as a single nerve from the posterior cord of the brachial plexus. It descends through the axilla, posterior to the axillary vein, and then runs parallel to the vascular pedicle of the latissimus dorsi muscle ${ }^{[38,39]}$. 


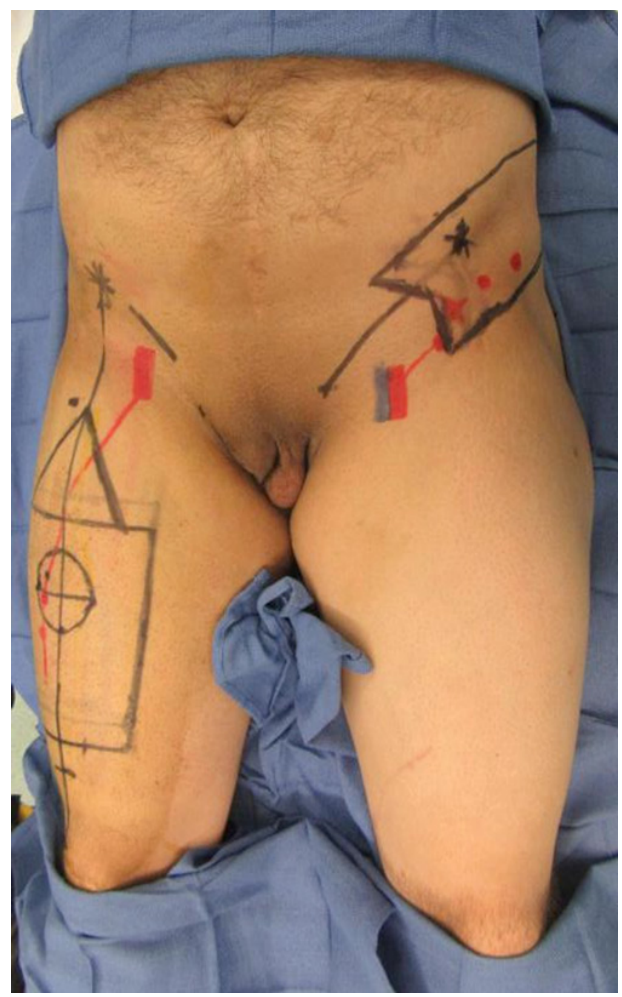

Figure 5. Preoperative markings for phalloplasty using a SCIAP flap for urethral reconstruction combined with an anterolateral thigh flap. SCIAP: superficial circumflex iliac artery perforator

Potential advantages of the MLD flap include its reliable vascular pedicle, large surface area, and minimal donor site morbidity. Proponents note maintenance of flap bulk which may enhance retention of subsequent prosthetic devices ${ }^{[40,41]}$. Overall, $93.8 \%$ of patients report being satisfied with their phallus following surgery ${ }^{[7]}$. The primary disadvantage of the MLD flap was the lack of orgasmic sensibility ${ }^{[40]}$. A literature review reported sensory function in 17 patients, yet $100 \%$ of patients reported tactile sensation following the procedure ${ }^{[7]}$. No studies examining erogenous sensation have been published.

The osteocutaneous fibula flap (OCFF) was first described in 1993 as a phalloplasty option to achieve neophallic rigidity without the use of a prosthesis ${ }^{[7]}$. The flap is based on the peroneal artery and may be harvested with the sural nerves ${ }^{[7,42]}$. The sural (or short saphenous) nerve arises from the medial sural cutaneous nerve between the two head of the gastrocnemius muscle. It travels superficial to the muscle until the middle of the leg, where it joins the sural communicating branch of the common fibular nerve. It then travels to the lateral malleolus, providing sensory innervation of the posterior-lateral leg ${ }^{[43,44]}$. Tactile and erogenous sensation have been reported following OCFF phalloplasty ${ }^{[7,42]}$, and patients reported feeling "good to very good" with sexual intercourse following this procedure ${ }^{[42]}$.

The superficial circumflex iliac artery perforator flap (SCIAP), often used in conjunction with other flaps, is another option for phalloplasty procedures [Figure 5] ${ }^{[45-47]}$. The SCIAP flap is based on perforating vessels from the superficial circumflex iliac artery, a branch of the external iliac/superficial femoral artery. It is not commonly used as a sensate flap in phalloplasty procedures. However, Iida et al ${ }^{[48]}$ describe the use of a sensate SCIAP flap in head and neck reconstruction using the lateral cutaneous branch of an intercostal nerve. Potential advantages of this flap include a concealed donor site, minimal donor-site morbidity, and the ability to thin the flap at the time of harvest ${ }^{[48,49]}$. 
Before the advent of microsurgery, pedicled abdominal flaps, such as the suprapubic phalloplasty, were more commonly utilized. Abdominal flaps are based upon the epigastric vessels ${ }^{[7,50]}$, and generally performed as a two-stage procedure; tubularization of the abdominal skin forms the shaft, and a skin graft is used for subsequent urethral reconstruction ${ }^{[7]}$. These flaps are considered non-sensate, as no direct nerve coaptations are performed. In general, abdominal flaps have fallen out of favor due to higher complication rates, lack of sensation, less favorable aesthetics results, and their general use as shaft only procedures ${ }^{[7,37]}$. However, $95 \%$ of patients report being satisfied with abdominal-based phalloplasty procedures ${ }^{[50]}$.

\section{SENSORY INNERVATION OF THE VULVA AND CLITORIS}

Understanding the innervation of the vulva and clitoris is integral to achieving successful phallic reconstruction. The ilioinguinal nerve, with the iliohypogastric nerve, arises as a single trunk from the first spinal lumbar nerve [Figure 4]. On the lateral border of the iliopsoas, the two nerves separate. The ilioinguinal nerve courses between the transverse and internal oblique abdominis muscle before entering the inguinal canal. The ilioinguinal nerve provides sensory innervation to the skin overlying the inguinal ligament, the pubis, the superomedial region of the thigh, and the labia majora or scrotum ${ }^{[51,52]}$.

The iliohypogastric nerve initially travels on the anterior surface of the quadratus lumborum muscle. It then travels in the plane between the transversus abdominis and internal oblique muscles. The lateral cutaneous branch provides sensation to the posterolateral gluteal skin. The anterior cutaneous branch courses through the internal oblique muscle in a downward and medial fashion before entering the external oblique muscle. The anterior cutaneous branch provides sensation to the skin in the pubic region ${ }^{[44]}$.

The genitofemoral nerve arises from the first and second spinal lumbar roots. As it descends into the true pelvis, the nerve branches into a genital and femoral branch at the medial aspect of the inguinal ligament. The former accompanies the round ligament or spermatic cord and supplies sensation to the skin of the mons pubis and the labia majora or the upper part of the scrotum, respectively. The femoral branch provides sensation to the anterolateral thigh ${ }^{[52]}$.

Somatic innervation to the lower urogenital system is provided by the pudendal nerve [Figure 6]. The pudendal nerve travels between the piriformis and coccygeus muscles. It then exits the pelvic cavity through the greater sciatic foramen. At the level of the ischium, it courses inferomedial to the sacrospinous ligament to re-enter the true pelvis via the lesser sciatic foramen. It then enters the pudendal canal ${ }^{[53]}$.

The pudendal nerve travels on the dorsal surface of the cavernous bodies of the clitoris, before innervating the glans clitoris [Figure 6]. The right and left dorsal clitoral nerves initially exist as two separate bundles that fan out laterally on the clitoral bodies ${ }^{[54]}$. Proximally, the dorsal nerves of the clitoris extend around the tunica of the clitoral bodies. There is extensive innervation at the 11 and 1 oclock positions, with a relative lack of nerves along the dorsal midline of the clitoral body (12 o'clock position $)^{[55-57]}$.

\section{MECHANISMS AND ASSESSMENTS OF FLAP REINNERVATION}

Flaps achieve sensation through two mechanisms ${ }^{[58]}$. The first mechanism is referred to as the "peripheral way" and describes sensory recovery when a nerve coaptation is not performed. For example, tactile and temperature sensation may be restored as nerves propagate from the wound margin and/or the recipient bed $^{[59]}$. The second pathway, called the "central way" is based on nerve coaptations between donor and recipient nerves. This technique typically results in improved sensory recovery and forms the basis of reinnervation strategies for phalloplasty procedures [Figure 7].

The ability to achieve tactile and/or erogenous sensation is affected by both the accuracy of nerve coaptation and the nerve's regeneration capacity. Nerve coaptation techniques have not been systematically 


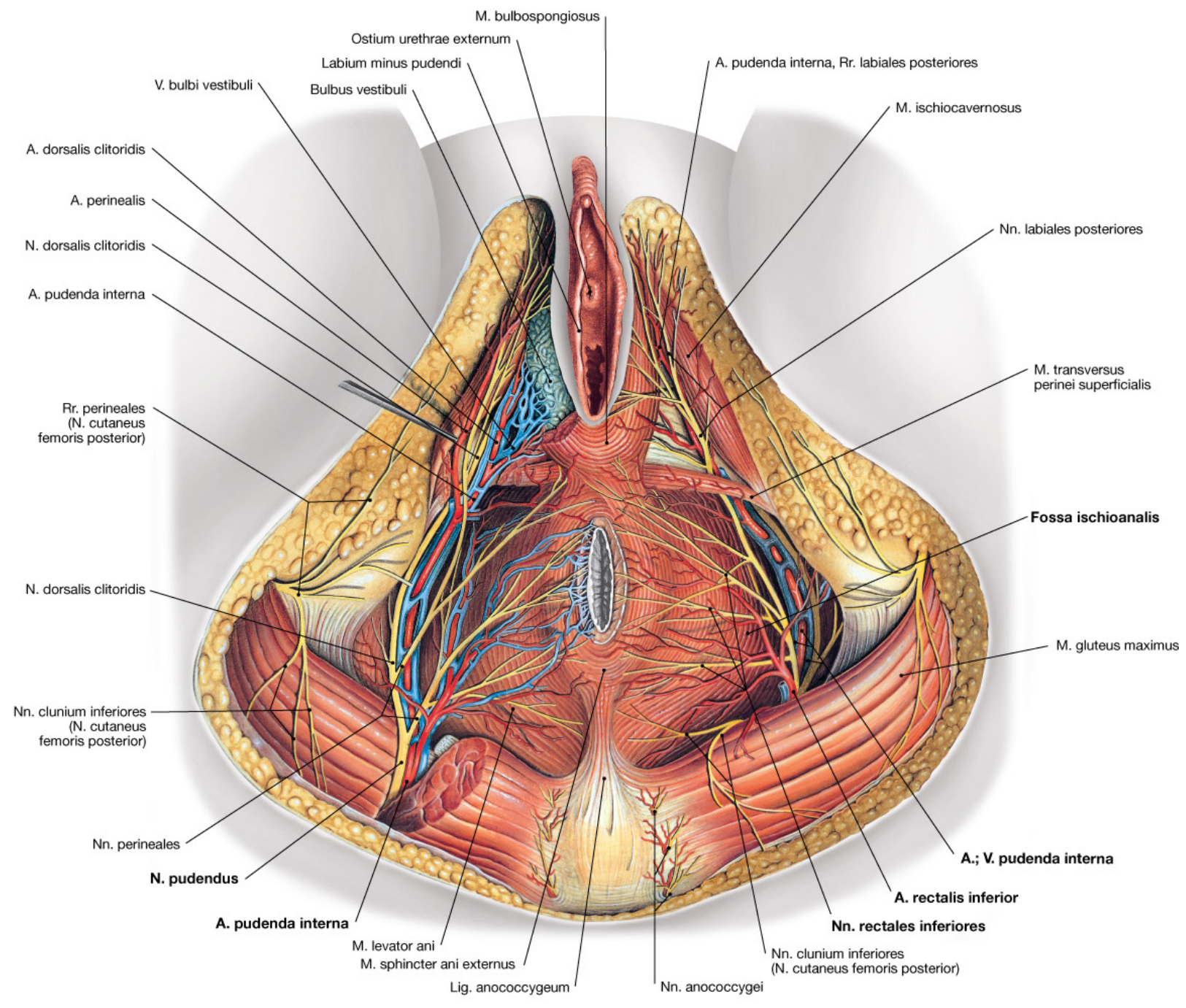

Paulsen/Waschke: Sobotta - Atlas der Anatomie, 24. A. 2017 Elsevier GmbH

Figure 6. Nerves and blood vessels of the female perineum
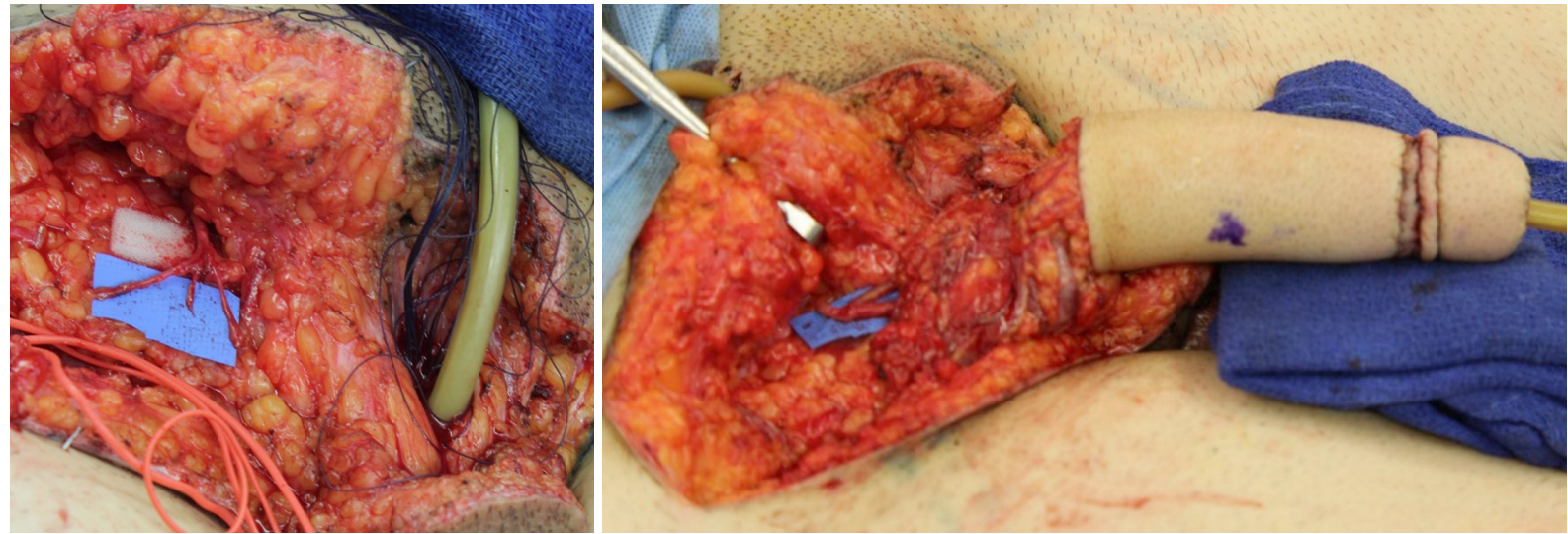

Figure 7. Urethral inset, vascular anastomoses, and neurroraphies of the neophallus using a radial forearm free flap 
studied in the field of gender affirmation surgery. A suture-only epineurial nerve repair remains the mainstay of care. An end-to-end repair is usually performed, but end-to-side and epineural sleeve repairs have been described ${ }^{[60]}$. When a tension-free coaptation is not possible, synthetic or biological conduits may be used ${ }^{[61]}$. In the field of peripheral nerve surgery, connector-assisted coaptations may decrease operative time, improve sensory outcomes, and decrease pain ${ }^{[62]}$. Multiple pharmacologic agents, such as AcetylL-carnitine, testosterone, and various growth factors have been investigated as a means to enhance nerve regeneration ${ }^{[63,64]}$. New approaches and techniques are under investigation, and the role of molecular, stem cell-based or gene therapies in nerve regeneration may play an important role in the future ${ }^{[65]}$.

The restoration of protective or tactile sensation is important in helping to avoid incidental injuries to the neophallus, but also in facilitating retention of an erectile prosthesis ${ }^{[24,29,58]}$. In addition, consistent with reports of penile reconstruction in cisgender $\operatorname{men}^{[11]}$, restoration of tactile sensation contributes to the orgasm experience in transgender men ${ }^{[29]}$. To achieve tactile or protective sensation, the recipient flap sensory nerve is typically coapted to the donor ilioinguinal nerve $e^{[15,22,24,25,28-30]}$.

There is no consistent method of reporting or assessing tactile sensation following phalloplasty procedures. In general, tactile sensation returns $\sim 1$ year following surgery ${ }^{[15,22]}$, however, Fang et al ${ }^{[28]}$ reported sensory recovery approximately 6 months following surgery. Selvaggi et al. ${ }^{[29]}$ reported pressure thresholds over the glans and corona of the neophallus (RFF) comparable to penile controls. Vibratory thresholds were consistent with the restoration of tactile sensitivity. However, these thresholds were high in comparison to penile controls, indicating that sensation was low following this procedure. Kim et al. ${ }^{[22]}$ reported outcomes of 40 transgender men undergoing phalloplasty with a radial forearm osteocutaneous flap. In their series, the medial antebrachial cutaneous nerve was coapted to the ilioinguinal nerve, and the lateral antebrachial cutaneous nerve was coapted to the deep pudendal or dorsal clitoral nerve. Sensation was assessed using the Zachary and Holmes scheme (ranging from So to S4). At a 12-month follow-up, all patients recovered tactile sensation greater than S2. This indicated a minimum recovery of pain and some touch sensibility. Monstrey et al ${ }^{[24]}$ used identical techniques in their cohort of 287 - of mostly transgender male-patients. After a year, all patients had regained tactile sensitivity.

A common strategy designed to provide erogenous sensation in phalloplasty procedures involves the coaptation of a flap sensory nerve to the dorsal pudendal nerve or the dorsal clitoral nerve $e^{[15,22,24,29]}$. Coaptations using the medial antebrachial cutaneous nerve or the lateral antebrachial cutaneous nerve are the two most commonly reported techniques ${ }^{[15]}$. It is theorized that nerve coaptations to the dorsal clitoral nerve allow the patient to reach orgasm from direct erogenous stimulation following the clitoral nerve pathway ${ }^{[29]}$. Oftentimes, the ilioinguinal nerve is used as a donor nerve to achieve tactile or protective sensibility and one branch of the dorsal clitoral nerve is used as a donor nerve to achieve erogenous sensation ${ }^{[15,24,29]}$. This technique leaves one dorsal clitoral nerve intact and untouched. The denuded glans clitoris is then buried at the base of the neophallus. Morrison et al. ${ }^{[15]}$ postulate that even with two independent nerve coaptations, the sensation of the reconstructed neophallus differs from that of cisgender men; however, no direct comparisons have been reported. Some authors advocate using only the dorsal clitoral nerves for the restoration of both tactile and erogenous sensation ${ }^{[8,10,23,26,31,34,42,66]}$. This follows the reconstructive concepts employed in cisgender men undergoing penile reconstruction ${ }^{[11,35,58,67-69]}$.

Despite few studies using validated measures to assess tactile sensation, reports of sensation, independent of flap type, are reported in the majority of transgender men (83\%-100\%) following phalloplasty ${ }^{[8,26,31,34,42,66]}$. Rubino et al. ${ }^{[34]}$ reported on the use of an ALT flap in one transgender man. In this case, the lateral femoral cutaneous nerve was coapted, end-to-side, to one of the dorsal nerves of the clitoris. Six months after the procedure, tactile sensation along the shaft of the neophallus was reported. Sensory threshold measurements for temperature and vibration were all within the normal range, and the patient experienced 


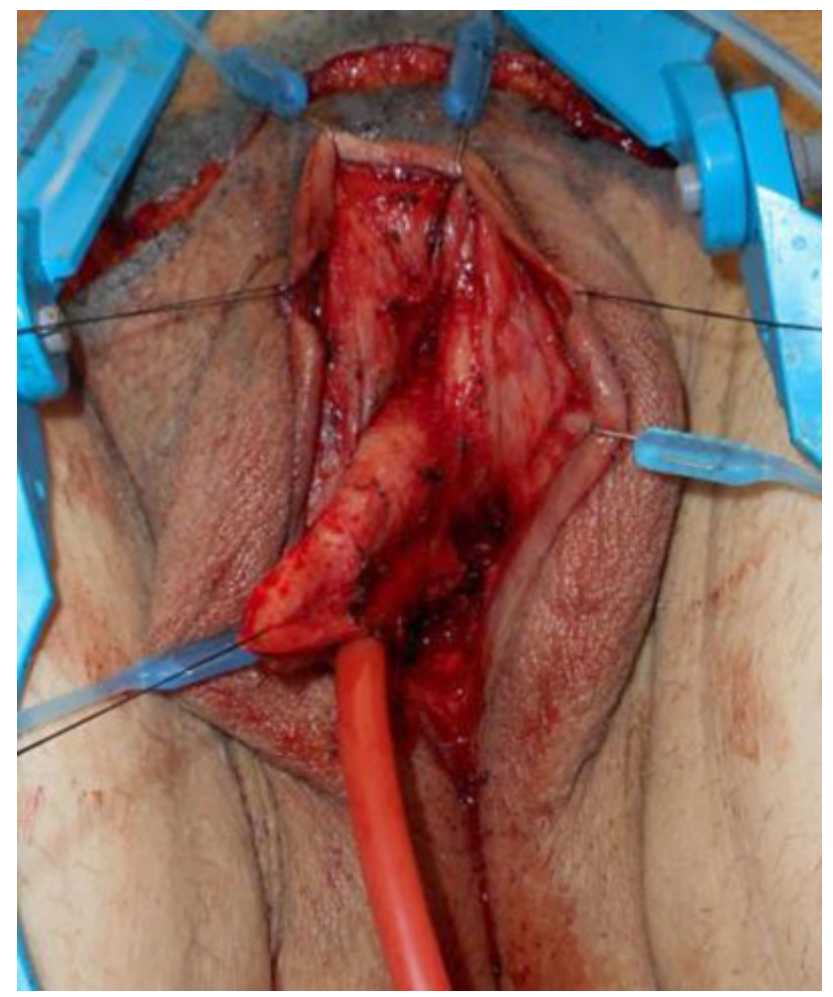

Figure 8. The clitoris de-epithelialized during the phalloplasty procedure

erogenous stimulation during intercourse. In their series, Ascha et al ${ }^{[23]}$ described outcomes of 64 transgender men undergoing an ALT flap with coaptation of the lateral femoral cutaneous nerve to the dorsal clitoral nerve, and 149 transgender men undergoing RFF with coaptation of the dorsal clitoral nerve to branches of the antebrachial cutaneous nerves. At 6 months follow up, 1 patient (1.6\%) in the ALT group and 2 (1.3\%) patients in the RFF group had not gained any sensation. Papadopulos et al ${ }^{[42]}$ reported on the outcomes of 32 osteocutaneous fibula flap phalloplasties involving the coaptation of sural nerve branches or subcutaneous nerve branches to the dorsal clitoral nerves. They report "acceptable" tactile and erogenous sensation in all patients at 6 months following the procedure. In one study of 56 RFF phalloplasties ${ }^{[28]}$, nerve coaptations were performed to the ilioinguinal and iliohypogastric nerves. The authors report the return of only tactile sensation, with minimal erogenous sensation noted.

Many surgeons postulate that preservation of the clitoris allows and preserves erogenous sensibility and hence, orgasmic function following phalloplasty ${ }^{[15]}$. As such, one branch of the dorsal clitoral nerve is typically left intact to maintain clitoral sensation ${ }^{[10,15]}$. The denuded or de-epithelialized clitoris is buried at the base of the neophallus to provide an additional source of erogenous sensation [Figures 8 and 9] $]^{[7,8,10,15,28,29,42,70]}$. Monstrey et al. ${ }^{[24]}$ describe burying the de-epithelialized clitoris above the pubic symphysis. With this technique, it is thought that manipulation of the base of the neophallus during penetrative intercourse or masturbation allows for the stimulation of the buried clitoris. Other authors describe incorporating the clitoral hood into the neoscrotum to preserve as much original erogenous sensitivity as possible ${ }^{[29,30]}$.

Other authors describe placement of the clitoris on the shaft of the neophallus ${ }^{[2,71]}$ or at the junction of the neoscrotum and the inner thigh so as to increase stimulation during penetrative intercourse ${ }^{[72]}$. Garaffa et al ${ }^{[25]}$ report offering two options for clitoral management during phalloplasty procedures. One option was to leave the clitoris exteriorized so as facilitate manipulation, and the second option entails burying the deepithelialized clitoris beneath the skin. Patients may select the first option due to a concern that clitoral 

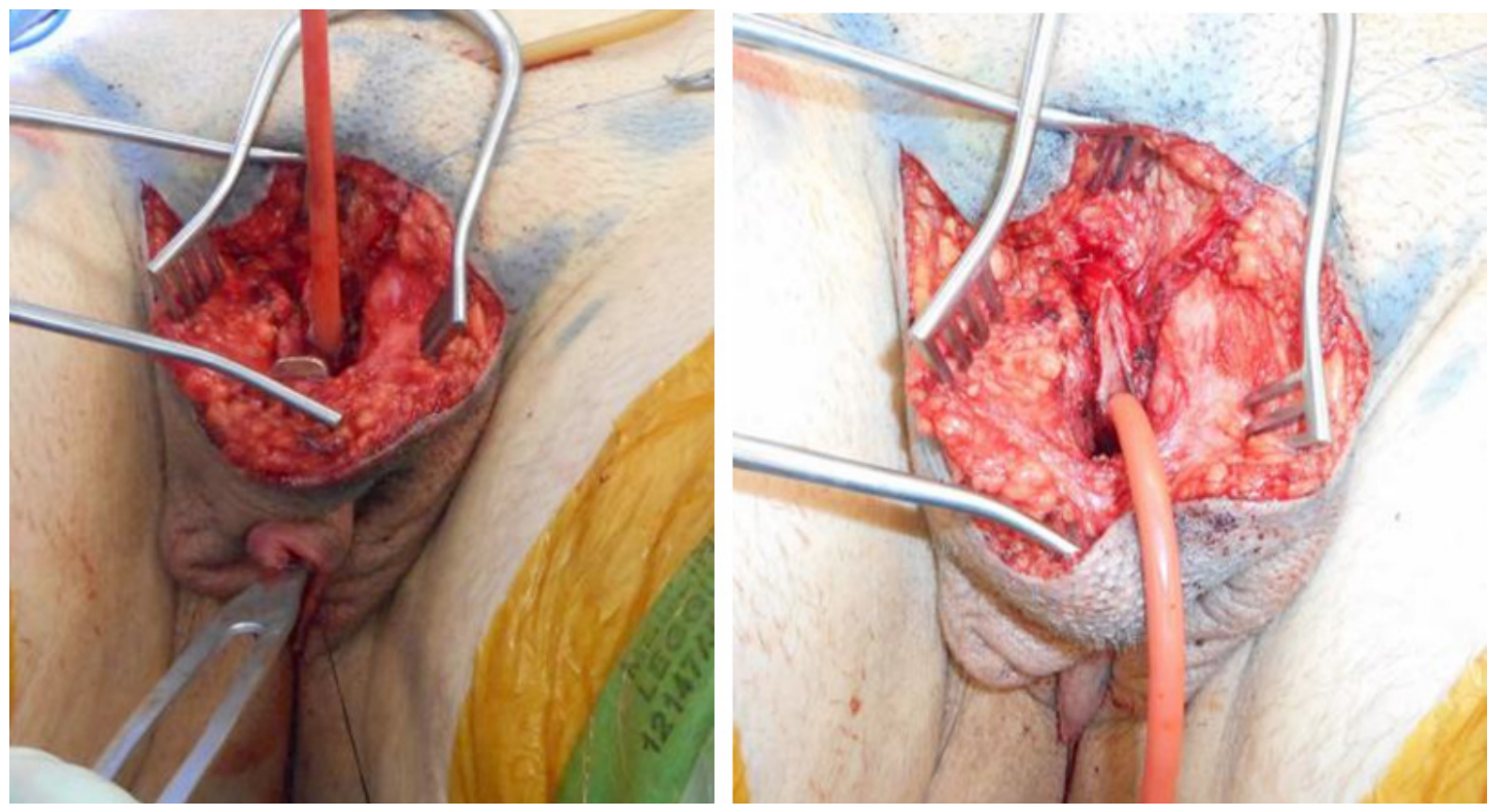

Figure 9. The clitoral-urethral construct transferred subcutaneously into position at the pubic symphysis

transposition may lead to a loss of pre-existing erogenous sensation. Clitoral transposition has not been found to result in a loss of ability to achieve orgasm with direct stimulation, and in these individuals, erogenous sensation remains consolidated outside of the neophallus ${ }^{[8]}$. Some surgeons postulate that placing the clitoris more superficially, just below the skin surface, rather than deeper, on the pubic symphysis, leaves it more accessible for direct stimulation and may enhance postoperative sexual function ${ }^{[8]}$. Despite this, no studies have compared the various techniques of clitoral placement.

Some patients report experiencing erogenous sensibility on the shaft of the neophallus during selfstimulation or penetrative intercourse $e^{[8,10,30,34,42]}$. Some transgender men report masturbating their neophallus regardless of whether or not they have undergone clitoral transposition and also report the ability to achieve orgasm with stimulation of the neophallus itself ${ }^{[8]}$. These findings are based on subjective patient reports rather than validated instruments. As such, it is difficult to discern the mechanism by which orgasmic function is attained. Future research is required to evaluate outcomes and elucidate the role by which various nerve coaptations result in orgasmic capability ${ }^{[15]}$.

\section{DISCUSSION}

Current innervation strategies are based on the premise that nerve coaptations to the dorsal pudendal or dorsal clitoral nerves and the ilioinguinal nerves will elicit erogenous and tactile sensation, respectively ${ }^{[29]}$. However, the ability to compare techniques is limited by a lack of standardized measures ${ }^{[15]}$. In a recent literature review ${ }^{[15]}$, recovered sensibility, whether tactile or erogenous, was found to be similar regardless of the choice of donor nerve. This finding is consistent with patient reports ${ }^{[8,10,22-24,26,29,31,34,42,66]}$. These findings suggest that the choice of donor nerve may also have little impact on post-surgical tactile or erogenous sensory outcomes ${ }^{[15]}$. This has led some surgeons to leave the dorsal clitoral nerves untouched, and simply bury the denuded clitoris within the base of the flap. While this technique may not lead to erogenous sensation along the shaft of the neophallus, it may reduce the possibility of a loss of erogenous sensation ${ }^{[28]}$. Conversely, other surgeons may advocate the importance of coaptation to the dorsal clitoral nerve so as to provide erogenous sensation to the neophallic shaft ${ }^{[8,10,30,34,42]}$. Doria-Medina et al ${ }^{[30]}$ reported functional 
neuroimaging (MRI) findings following RFF phalloplasty in a transgender man after coaptation of the $\mathrm{LABC}$ and $\mathrm{MABC}$ to the dorsal clitoral and ilioinguinal nerves, respectively. Bilateral cortical activation was identified in areas suspected to play a role in the conscious perception of sexual stimuli. Their findings suggest somatotopic arrangements in the groin and clitoris after stimulating the neophallus. While these data are indicative of successful nerve coaptation, no significant activation in the insular region was noted. This is the area that typically activates when stimuli are perceived as sexual. Also, stroking of the neophallus and groin led to diffuse and non-assessable findings on fMRI. These findings could not be further analyzed, making it difficult to understand the extent by which erogenous sensation contributes to these findings.

The "sensory upgrading phenomenon" offers additional thoughts as to the selection of donor and recipient nerves ${ }^{[58,69]}$. This concept is based on the finding that neurotized free flaps have better sensitivity at their new location as compared to their native site. This suggests that the sensory representation of the donor nerve in the cerebral cortex plays a more important role than the recipient nerve itself ${ }^{[58,69]}$. This is supported by findings in cisgender men which demonstrate decreased two-point discrimination in the non-operated donor site forearms as compared to the reinnervated radial forearm free flaps used for phalloplasty ${ }^{[58]}$. It is also consistent with the hypothesis proposed by Morrison et al. ${ }^{[15]}$ which states that erogenous sensation is more dependent on the cortical interpretation of neural input rather than the choice of the recipient nerve. In other words, perhaps the choice of donor nerve is more important than the choice of recipient nerve. Regardless, many factors likely play a role in sensory recovery ${ }^{[58,69]}$, and most flaps report overall good sensory outcomes. Flap choice may play a less important role than previously thought. An additional hypothesis proposed by Gilbert et al. ${ }^{[71]}$ is the potential for "dissociated sensibility". This phenomenon is explained as the ability of the brain to interpret other peripheral stimuli as erogenous in nature. The authors hypothesize that the "cortex feels what it wants to feel" despite a scarcity of somatosensory input. They cite this as a possible mechanism for achieving erogenous sensation following phalloplasty procedures. This concept is also alluded to by Hage and De Graaf ${ }^{[31]}$ when they hypothesized that cortical control exerts a "tremendous" influence regarding erogenous stimulation. These authors state that nerve coaptation should not be expected to result in erogenous phallic sensibility. Since four of their eleven patients reported erogenous sensation in some parts of their neophallus, they postulated that cortical control must play an important role in contributing to erogenous sensation. Further studies may help to delineate how these factors contribute to the sexual experience following phalloplasty.

Additionally, preservation and placement of the clitoris such that it is readily amenable to stimulation may be important in orgasmic potential following phalloplasty. Although studies comparing clitoral placement are lacking, the majority of studies report that placing the denuded clitoris at the base of the neophallus helps to consolidate the orgasm experience within the neophallus ${ }^{[7,8,10,15,28,29,42,70]}$. Therefore, a hybrid approach, combining tactile or protective sensation through coaptation to the ilioinguinal nerve and achieving erotic sensation by either coaptation to the dorsal clitoral nerve or preservation of the denuded clitoris may offer the most sensible approach.

Currently, no validated outcome instruments exist by which to evaluate erogenous sensation in transgender men following phalloplasty ${ }^{[15]}$. Erogenous sensory outcomes have relied on patient reports, such as the ability to achieve orgasm ${ }^{[8,22,29]}$. Selvaggi et al.$^{[2]}$ noted that $100 \%$ of patients were able to experience orgasm following RFF phalloplasty. These findings have been corroborated by other surgeons ${ }^{[8,15,22,24]}$. Monstrey et al. ${ }^{[24]}$ reported $>80 \%$ improvement in sexuality and greater sexual satisfaction following RFF phalloplasty. Patients reported improved sexual satisfaction and greater ease in reaching orgasm. While the ability to reach orgasm may be correlated with direct stimulation of the clitoral nerve pathway, the presence of tactile sensation may facilitate orgasmic potential. Garcia et al. ${ }^{[8]}$ cite patient reports identifying "purely psychological" pleasure and enhanced orgasm quality derived from self-stimulation of the phallus. 100\% of patients in the RFF phalloplasty cohort and $90 \%$ of patients in the suprapubic phalloplasty cohort reported: 
(1) masturbating their neophallus; and (2) achieving orgasm with stimulation of the phallus alone. This was independent of the treatment of the clitoris and supports the concept that additional factors contribute to the ability to achieve orgasm. One potential contributing factor is the improvement that occurs in one's identity following phalloplasty ${ }^{[12]}$. van de Grift et al. ${ }^{[12]}$ report the development of positive self-esteem and affirmation of a masculine identity following phalloplasty. This may facilitate engagement in and, enjoyment of, sexual activity including increased sexual initiative and pleasure.

\section{CONCLUSION}

While there is no consensus as to the optimal flap or the optimal pattern of innervation, tactile, and erogenous sensation following phalloplasty is an important goal. Understanding the relevant flap and donor site anatomy is important in optimizing outcomes, but there are likely multiple factors that contribute to both sexual satisfaction and orgasmic potential. Additional studies comparing various nerve coaptation strategies will help elucidate these issues.

\section{DECLARATIONS}

\section{Authors' contributions}

Literature review, writing: Hontscharuk R, Siotos C

Generation of an idea, editing, writing, photo contributor: Schechter LS

\section{Availability of data and materials}

All referenced publications can be searched and found on PubMed. These papers are available to all readers through published journal websites.

\section{Financial support and sponsorship}

None.

\section{Conflicts of interest}

Hontscharuk R and Siotos C have no potential conflicts; Schechter LS receives royalties from textbooks from Elsevier and Springer publishers.

\section{Ethical approval and consent to participate}

Not applicable.

\section{Consent for publication}

Consent for publication has been obtained from the publisher of the anatomy textbook.

\section{Copyright}

(c) The Author(s) 2020.

\section{REFERENCES}

1. Meerwijk EL, Sevelius JM. Transgender population size in the United States: a meta-regression of population-based probability samples. Am J Public Health 2017;107:e1-8.

2. Winter S, Diamond M, Green J, et al. Transgender people: health at the margins of society. Lancet 2016;388:390-400.

3. Tollinche LE, Walters CB, Radix A, et al. The perioperative care of the transgender patient. Anesth Analg 2018;127:359-66.

4. Tran BNN, Epstein S, Singhal D, et al. Gender affirmation surgery: a synopsis using American College of Surgeons National Surgery Quality Improvement Program and National Inpatient Sample Databases. Ann Plast Surg 2018;80:S229-35.

5. American Society of Plastic Surgeons. Plastic Surgery Statistics. Available from: https://www.plasticsurgery.org/news/plastic-surgerystatistics. [Last accessed on 12 Oct 2020]

6. Al-Tamimi M, Pigot GL, Elfering L, et al. Genital gender-affirming surgery in transgender men in the Netherlands from 1989 to 2018: the evolution of surgical care. Plast Reconstr Surg 2020;145:153e-61. 
7. Morrison SD, Shakir A, Vyas KS, et al. Phalloplasty: a review of techniques and outcomes. Plast Reconstr Surg 2016;138:594-615.

8. Garcia MM, Christopher NA, De Luca F, Spilotros M, Ralph DJ. Overall satisfaction, sexual function, and the durability of neophallus dimensions following staged female to male genital gender confirming surgery: the Institute of Urology, London U.K. experience. Transl Androl Urol 2014;3:156-62.

9. Al-Tamimi M, Pigot GL, van der Sluis WB, et al. The surgical techniques and outcomes of secondary phalloplasty after metoidioplasty in transgender men: an international, multi-center case series. J Sex Med 2019;16:1849-59.

10. Hage JJ, Bloem JJ, Suliman HM. Review of the literature on techniques for phalloplasty with emphasis on the applicability in female-tomale transsexuals. J Urol 1993;150:1093-8.

11. Cheng KX, Hwang WY, Eid AE, et al. Analysis of 136 cases of reconstructed penis using various methods. Plast Reconstr Surg 1995;95:1070-80; discussion 1081-4.

12. van de Grift TC, Pigot GLS, Kreukels BPC, Bouman MB, Mullender MG. Transmen's experienced sexuality and genital gender-affirming surgery: findings from a clinical follow-up study. J Sex Marital Ther 2019;45:201-5.

13. Overgoor ML, de Jong TP, Kon M. Restoring tactile and erogenous penile sensation in low-spinal-lesion patients: procedural and technical aspects following 43 TOMAX nerve transfer procedures. Plast Reconstr Surg 2014;134:294e-301.

14. Alwaal A, Breyer BN, Lue TF. Normal male sexual function: emphasis on orgasm and ejaculation. Fertil Steril 2015;104:1051-60.

15. Morrison SD, Massie JP, Dellon AL. Genital sensibility in the neophallus: getting a sense of the current literature and techniques. J Reconstr Microsurg 2019;35:129-37.

16. Masear VR, Meyer RD, Pichora DR. Surgical anatomy of the medial antebrachial cutaneous nerve. J Hand Surg Am 1989;14:267-71.

17. Race CM, Saldana MJ. Anatomic course of the medial cutaneous nerves of the arm. J Hand Surg Am 1991;16:48-52.

18. Beldner S, Zlotolow DA, Melone CP Jr, Agnes AM, Jones MH. Anatomy of the lateral antebrachial cutaneous and superficial radial nerves in the forearm: a cadaveric and clinical study. J Hand Surg Am 2005;30:1226-30.

19. Bourne MH, Wood MB, Carmichael SW. Locating the lateral antebrachial cutaneous nerve. J Hand Surg Am 1987;12:697-9.

20. Safa B, Lin WC, Salim AM, Deschamps-Braly JC, Poh MM. Current concepts in masculinizing gender surgery. Plast Reconstr Surg 2019;143:857e-71.

21. Frey JD, Poudrier G, Chiodo MV, Hazen A. An update on genital reconstruction options for the female-to-male transgender patient: a review of the literature. Plast Reconstr Surg 2017;139:728-37.

22. Kim SK, Lee KC, Kwon YS, Cha BH. Phalloplasty using radial forearm osteocutaneous free flaps in female-to-male transsexuals. J Plast Reconstr Aesthet Surg 2009;62:309-17.

23. Ascha M, Massie JP, Morrison SD, Crane CN, Chen ML. Outcomes of single stage phalloplasty by pedicled anterolateral thigh flap versus radial forearm free flap in gender confirming surgery. J Urol 2018;199:206-14.

24. Monstrey S, Hoebeke P, Selvaggi G, et al. Penile reconstruction: is the radial forearm flap really the standard technique? Plast Reconstr Surg 2009;124:510-8.

25. Garaffa G, Christopher NA, Ralph DJ. Total phallic reconstruction in female-to-male transsexuals. Eur Urol 2010;57:715-22.

26. Leriche A, Timsit MO, Morel-Journel N, et al. Long-term outcome of forearm flee-flap phalloplasty in the treatment of transsexualism. BJU Int 2008;101:1297-300.

27. Babaei A, Safarinejad MR, Farrokhi F, Iran-Pour E. Penile reconstruction: evaluation of the most accepted techniques. Urol J 2010;7:71-8.

28. Fang RH, Lin JT, Ma S. Phalloplasty for female transsexuals with sensate free forearm flap. Microsurgery 1994;15:349-52.

29. Selvaggi G, Monstrey S, Ceulemans P, et al. Genital sensitivity after sex reassignment surgery in transsexual patients. Ann Plast Surg 2007;58:427-33.

30. Doria-Medina R, Carlsson $\AA$, Jönsson EH, et al. fMRI after phalloplasty with nerve anastomosis in a trans-man patient. Plast Reconstr Surg Glob Open 2017;5:e1353.

31. Hage JJ, De Graaf FH. Addressing the ideal requirements by free flap phalloplasty: some reflections on refinements of technique. Microsurgery 1993;14:592-8.

32. Ribuffo D, Cigna E, Gargano F, Spalvieri C, Scuderi N. The innervated anterolateral thigh flap: anatomical study and clinical implications. Plast Reconstr Surg 2005;115:464-70.

33. Gilroy A, MacPherson B, Ross L. Superficial Nerves \& Vessels of the Lower Limb. Atlas of Anatomy, 2nd ed. Thieme, New York; 2012. pp. 458-9.

34. Rubino C, Figus A, Dessy LA, et al. Innervated island pedicled anterolateral thigh flap for neo-phallic reconstruction in female-to-male transsexuals. J Plast Reconstr Aesthet Surg 2009;62:e45-9.

35. Morrison SD, Son J, Song J, et al. Modification of the tube-in-tube pedicled anterolateral thigh flap for total phalloplasty: the mushroom flap. Ann Plast Surg 2014;72 Suppl 1:S22-6.

36. Felici N, Felici A. A new phalloplasty technique: the free anterolateral thigh flap phalloplasty. J Plast Reconstr Aesthet Surg 2006;59:153-7.

37. Heston AL, Esmonde NO, Dugi DD 3rd, Berli JU. Phalloplasty: techniques and outcomes. Transl Androl Urol 2019;8:254-65.

38. Tubbs RS, Loukas M, Shahid K, et al. Anatomy and quantitation of the subscapular nerves. Clin Anat 2007;20:656-9.

39. Chu B, Bordoni B. Anatomy, Thorax, Thoracodorsal Nerves. In: StatPearls [Internet]. Treasure Island (FL): StatPearls Publishing; 2020. Available from: https://www.ncbi.nlm.nih.gov/books/NBK539761/. [Last accessed on 12 Oct 2020]

40. Perovic SV, Djinovic R, Bumbasirevic M, Djordjevic M, Vukovic P. Total phalloplasty using a musculocutaneous latissimus dorsi flap. BJU Int 2007;100:899-905; discussion 905.

41. Dennis M, Granger A, Ortiz A, et al. The anatomy of the musculocutaneous latissimus dorsi flap for neophalloplasty. Clin Anat 2018;31:152-9. 
42. Papadopulos NA, Schaff J, Biemer E. The use of free prelaminated and sensate osteofasciocutaneous fibular flap in phalloplasty. Injury 2008;39 Suppl 3:S62-7.

43. Popieluszko P, Mizia E, Henry BM, et al. The surgical anatomy of the sural nerve: an ultrasound study. Clin Anat 2018;31450-5.

44. Standring S, Gray H. Gray's anatomy: the anatomical basis of clinical practice. Edinburgh: Churchill Livingstone/Elsevier; 2008.

45. Al-Tamimi M, Pigot GL, Ronkes B, et al. The first experience of using the pedicled labia minora flap for urethral lengthening in transgender men undergoing anterolateral thigh and superficial circumflex iliac artery perforator flap phalloplasty: a multicenter study on clinical outcomes. Urology 2020;138:179-87.

46. Veerman H, de Rooij FPW, Al-Tamimi M, et al. Functional outcomes and urological complications after genital gender affirming surgery with urethral lengthening in transgender men. J Urol 2020;204:104-9.

47. D'Arpa S, Claes K, Lumen N, et al. Urethral reconstruction in anterolateral thigh flap phalloplasty: a 93-case experience. Plast Reconstr Surg 2019;143:382e-92.

48. Iida T, Mihara M, Yoshimatsu H, Narushima M, Koshima I. Versatility of the superficial circumflex iliac artery perforator flap in head and neck reconstruction. Ann Plast Surg 2014;72:332-6.

49. Koshima I, Nanba Y, Tsutsui T, et al. Superficial circumflex iliac artery perforator flap for reconstruction of limb defects. Plast Reconstr Surg 2004;113:233-40.

50. Terrier JÉ, Courtois F, Ruffion A, Morel Journel N. Surgical outcomes and patients' satisfaction with suprapubic phalloplasty. J Sex Med 2014;11:288-98.

51. Ndiaye A, Diop M, Ndoye JM, et al. Emergence and distribution of the ilioinguinal nerve in the inguinal region: applications to the ilioinguinal anaesthetic block (about 100 dissections). Surg Radiol Anat 2010;32:55-62.

52. Hollinshead WH. Anatomy for Surgeons, Volume 2: The Back And Limbs. New York: Harper and Row; 1969.

53. Kaur J, Singh P. Pudendal nerve entrapment syndrome. 2020 Mar 5. Treasure Island (FL): StatPearls Publishing; 2020.

54. Baskin LS. Anatomical studies of the female genitalia: surgical reconstructive implications. J Pediatr Endocrinol Metab 2004;17:581-7.

55. Yucel S, De Souza A Jr, Baskin LS. Neuroanatomy of the human female lower urogenital tract. J Urol 2004;172:191-5.

56. Baskin LS, Erol A, Li YW, et al. Anatomical studies of the human clitoris. J Urol 1999;162:1015-20.

57. Tajkarimi K, Burnett AL. The role of genital nerve afferents in the physiology of the sexual response and pelvic floor function. J Sex Med 2011;8:1299-312.

58. Ma S, Cheng K, Liu Y. Sensibility following innervated free radial forearm flap for penile reconstruction. Plast Reconstr Surg 2011;127:235-41.

59. Waris T, Rechardt L, Kyösola K. Reinnervation of human skin grafts: a histochemical study. Plast Reconstr Surg 1983;72:439-47.

60. Siemionow M, Brzezicki G. Chapter 8: current techniques and concepts in peripheral nerve repair. Int Rev Neurobiol 2009;87:141-72.

61. Griffin JW, Hogan MV, Chhabra AB, Deal DN. Peripheral nerve repair and reconstruction. J Bone Joint Surg Am 2013;95:2144-51.

62. Ducic I, Safa B, DeVinney E. Refinements of nerve repair with connector-assisted coaptation. Microsurgery 2017;37:256-63.

63. Panagopoulos GN, Megaloikonomos PD, Mavrogenis AF. The present and future for peripheral nerve regeneration. Orthopedics 2017;40:e141-56.

64. Pabari A, Lloyd-Hughes H, Seifalian AM, Mosahebi A. Nerve conduits for peripheral nerve surgery. Plast Reconstr Surg 2014;133:1420-30.

65. Lin MY, Manzano G, Gupta R. Nerve allografts and conduits in peripheral nerve repair. Hand Clin 2013;29:331-48.

66. Khouri RK, Young VL, Casoli VM. Long-term results of total penile reconstruction with a prefabricated lateral arm free flap. J Urol 1998;160:383-8.

67. Ramesh S, Serjius A, Wong TB, Jagjeet S, John R. Two stage penile reconstruction with free prefabricated sensate radial forearm osteocutaneous flap. Med J Malaysia 2008;63:343-5.

68. Cheng KX, Zhang RH, Zhou S, et al. Cheng's method for reconstruction of a functionally sensitive penis. Plast Reconstr Surg 1997;99:8791; discussion 92.

69. Ma S, Liu Y, Chang T, Cheng K. Long-term follow-up of sensation recovery of the penis reconstructed by Cheng's method. Plast Reconstr Surg 2011;127:1546-52.

70. Schaff J, Papadopulos NA. A new protocol for complete phalloplasty with free sensate and prelaminated osteofasciocutaneous flaps: experience in 37 patients. Microsurgery 2009;29:413-9.

71. Gilbert DA, Williams MW, Horton CE, et al. Phallic reinnervation via the pudendal nerve. J Urol 1988;140:295-9.

72. Fang RH, Kao YS, Ma S, Lin JT. Phalloplasty in female-to-male transsexuals using free radial osteocutaneous flap: a series of 22 cases. Br J Plast Surg 1999;52:217-22. 